\title{
EXCRETION OF $\left[6-{ }^{14} \mathrm{C}\right] \mathrm{MEGESTROL}$ ACETATE (6 METHYL-17 ACETOXYPREGNA-4,6 DIENE, 3,20 DIONE) RELEASED FROM SUBCUTANEOUS SILASTIC IMPLANTS IN WOMEN
}

\author{
ELSIMAR M. GOUTINHO, DIRGEU A. M. FERREIRA, \\ HYARA PRATES AND FRED KINGL
}

Departments of Biochemistry and Obstetrics, Federal University of Bahia, Brazil

(Received 26th May 1970)

The use of a subcutaneous inert capsule containing a progestational steroid has been proposed recently for long-term control of fertility. The results of pilot studies (Groxatto, Diaz, Vera, Etchart \& Atria, 1969) indicate that, with this technique, it is possible to prevent conception without interfering with ovulation, apparently because the progestin is released slowly but continuously in very small amounts. It has been estimated that four to six silastic capsules (each containing $18 \mathrm{mg}$ of megestrol acetate) would effectively prevent conception for 1 year. However, the basis for this estimate was derived from our clinical data alone (Tatum, Coutinho, Adeodato Filho \& Sant'Ana, 1969) and for this reason the present investigation was undertaken. Here, the excretion rates of $\left[6 \cdot{ }^{14} \mathrm{C}\right]$ megestrol acetate are reported for post-menopausal women implanted with capsules containing the radioactive steroid in the same amount as in the capsules used for contraceptive purposes.

Dimethylpolysiloxane (Silastic 602-235 tubing, $1.5 \mathrm{~mm}$ inner diameter and $2.0 \mathrm{~mm}$ outer diameter, Dow Gorning Gorporation) was used. Segments of tubing, $20 \mathrm{~mm}$ in length, were filled with the labelled steroid and sealed at both ends with silastic medical adhesive silicone type A cement. Supplies of $\left[6-{ }^{14} \mathrm{C}\right]$ megestrol acetate (6-methyl-17 acetoxypregna-4,6 diene 3,20 dione) with a specific activity of $1076 \mathrm{~d} / \mathrm{min} / \mu \mathrm{g}$ were obtained from British Drug Houses Ltd, London.

The capsules, containing approximately $18 \mathrm{mg}\left[6-{ }^{14} \mathrm{C}\right]$ megestrol acetate, were steam sterilized and then introduced into the upper ventral aspect of the forearm through an 11-gauge trocar. Two capsules were inserted into each of eight post-menopausal patients. The patients had gynaecological cancer and were expected to benefit from the administration of the progestin. Two of these patients, who had endometrial cancer, had previously been given high doses of the compound in an attempt to reduce the growth of metastases. Urine was collected at each 24-hr interval and kept under refrigeration. The urinary $\mathrm{pH}$ was adjusted to 11 and the extracts prepared by agitating $50-\mathrm{ml}$ aliquots with $50 \mathrm{ml}$ of $\mathrm{n}$-butanol for $1 \mathrm{hr}$. Each aliquot was extracted three times with butanol; the extracts were then evaporated to a volume of $5 \mathrm{ml}$ and 
the radioactivity counted in a Packard Tri-Garb scintillation spectrometer Model 3003. The efficiency was $75 \%$ to $80 \%$ for ${ }^{14} \mathrm{G}$. The mean urinary excretion for the eight patients was highest during the week following the insertion of the two implants (Text-fig. 1). The excretion rates declined most rapidly during the first 30 days. The mean value of $8.4 \mu \mathrm{g} / 24 \mathrm{hr}$ on Day 1 of observation decreased to a mean of $3.7 \mu \mathrm{g} / 24 \mathrm{hr}$ on Day 30 . During the 2nd month, the decline continued but was less steep. At the end of 60 days, the mean excretion rate was in the range of $2 \mu \mathrm{g} / 24 \mathrm{hr}$. From the 60 th to 80 th day, the excretion rates remained at this level.

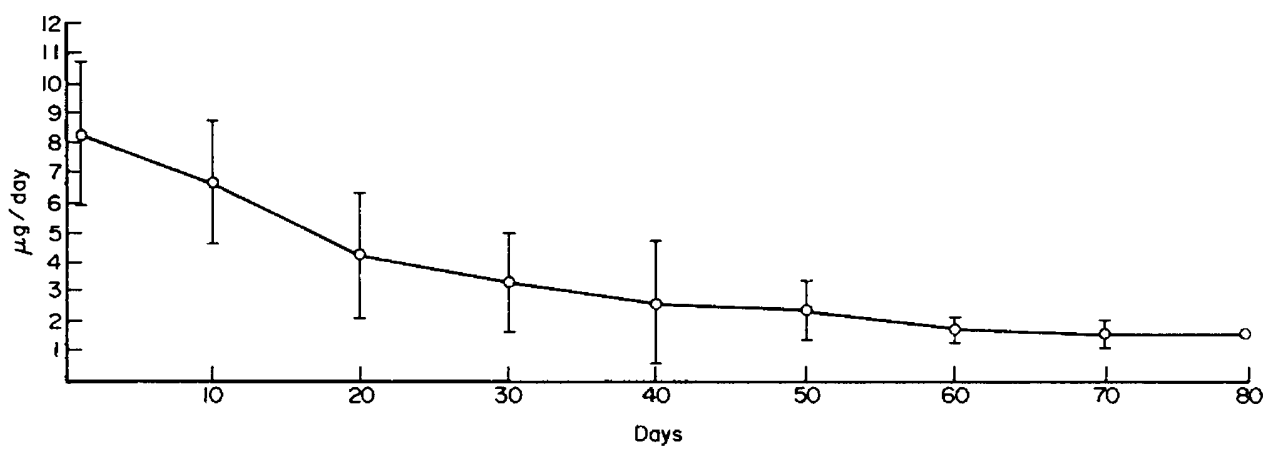

TEXT-FIG. 1. Urinary excretion of $\left[{ }^{14} \mathrm{G}\right]$ megestrol acetate in women. Mean and S.D. for eight patients during 80 days. Note that after 60 days, excretion rates level off around $3 \mu \mathrm{g} /$ day.

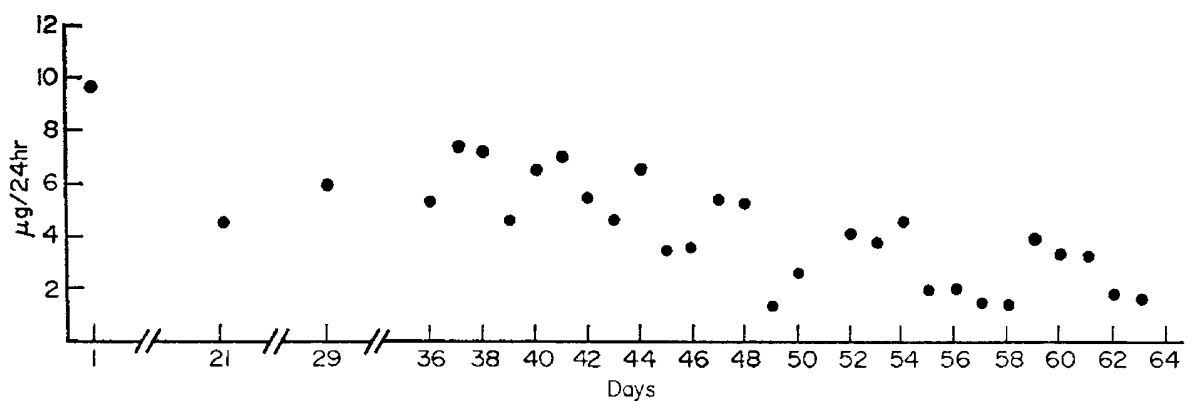

TEXT-FIG. 2. Daily urinary excretion of $\left[{ }^{14} \mathrm{C}\right]$ megestrol acetate in a 54-year-old menopausal patient (L.R.). Note the daily fluctuation and the slow decline in daily excretion.

The individual daily excretion was found to fluctuate widely. These variations were greatest during the 1st month, when daily excretion was higher. All the excretion rates determined for one patient over the 64 days following ${ }^{14} \mathrm{C}$ implantation are shown in Text-fig. 2. A high level of $10 \mu \mathrm{g} / 24 \mathrm{hr}$ was found on Day 1, this dropped to $4.8 \mu \mathrm{g}$ on Day 2 and was maintained at a level of 4 to 6 $\mu \mathrm{g}$ until Day 48. From Days 48 to 64 , the level ranged from 2 to $4 \cdot 8 \mu \mathrm{g} / 24 \mathrm{hr}$.

On the basis of the present results, it is estimated that the excretion of the $\left[{ }^{14} \mathrm{C}\right]$ megestrol acetate would be maintained at a 2- to $3-\mu \mathrm{g} / 24 \mathrm{hr}$ level for 200 days and possibly longer. The protracted release of this compound is confirmed by the fact that its clinical effectiveness is retained for 10 months, or longer. 
Where contraceptive effectiveness was evaluated, however, two implants failed to afford protection though four capsules provided a minimal effective dose for most patients. In these, the total daily excretion for megestrol acetate would be approximately 8 to $12 \mu \mathrm{g} / \mathrm{hr}$. The amount of megestrol acetate contained in four implants appeared to be sufficient to prevent conception without interfering with ovulation. Six of the present size implants, however, inhibited ovulation, as indicated by laboratory and clinical data. Although the eight patients in this study were post-menopausal and in some, liver and kidney function may have been compromised by metastatic involvement, the relative uniformity of all excretion patterns suggests that this compound was metabolized as in the normal individual. Lower activity implants in normal ovulatory patients will provide further long-term data.

This work was supported by the Ford Foundation.

\section{REFERENCES}

Groxatto, H., Diaz, S., Vera, R., Etchart, M. \& Atria, P. (1969) Fertility control in women with a progestogen released in microquantities from subcutaneous capsules. Am. J. Obstet. Gynec. 105, 1135.

Tatum, H. J., Coutinho, E. M., Adeodato Frzho, J. \& Sant'Ana, A. R. (1969) Acceptability of long term contraceptive steroid administration in humans by subcutaneous silastic capsules. $A m$. $\mathcal{F}$. Obstet. Gynec. 105, 1139. 